\title{
What's in a Font?: Ideological Perceptions of Typography
}

\section{Katherine Haenschen \& Daniel J. Tamul}

To cite this article: Katherine Haenschen \& Daniel J. Tamul (2019): What's in a Font?: Ideological Perceptions of Typography, Communication Studies, DOI: 10.1080/10510974.2019.1692884

To link to this article: https://doi.org/10.1080/10510974.2019.1692884

曲 Published online: 20 Dec 2019.

Submit your article to this journal 준

III Article views: 3565

Q View related articles ¿

View Crossmark data \lceil

This article has been awarded the Centre

for Open Science 'Open Data' badge.

This article has been awarded the Centre

for Open Science 'Open Materials' badge. 


\title{
What's in a Font?: Ideological Perceptions of Typography
}

\author{
Katherine Haenschen (1) and Daniel J. Tamul (1) \\ Department of Communication, Virginia Polytechnic Institute and State University, Blacksburg, Virginia, USA
}

\begin{abstract}
Although extensive political communication research considers the content of candidate messages, scholars have largely ignored how those words are rendered - specifically, the typefaces in which they are set. If typefaces are found to have political attributes, that may impact how voters receive campaign messages. Our paper reports the results of two survey experiments demonstrating that individuals perceive typefaces, type families, and type styles to have ideological qualities. Furthermore, partisanship moderates subjects' perceptions of typefaces: Republicans generally view typefaces as more conservative than Independents and Democrats. We also find evidence of affective polarization, in that individuals rate typefaces more favorably when perceived as sharing their ideological orientation. Results broaden our understanding of how meaning is conveyed in political communication, laying the groundwork for future research into the functions of typography and graphic design in contemporary political campaigns. Implications for political practitioners are also discussed.
\end{abstract}

\section{KEYWORDS}

Political communication; ideology; partisanship; typeface; graphic design

\section{Introduction}

Campaign logos, yard signs, and website designs are understood to convey meaning about candidates' images and personalities (Benoit \& Benoit, 2009; Billard, 2016; Cosgrove, 2012). Although ample political communication research considers the content of candidate messages, scholars have largely ignored how these words are rendered - specifically, the typefaces ${ }^{1}$ in which they are set. Though the American political press scrutinizes presidential candidates' font and logo choices (e.g., Heller, 2008; Jackson, 2012; O’Kane, 2019; Rainbird, 2012), academics have paid scant attention to these design items in the realm of politics, with Billard $(2016,2018)$ a notable exception. If typefaces can be shown to possess political qualities, typeface choice in candidate communication may impact the message received by voters. In this paper, we heed Billard's (2016) call to "further investigate the ways in which the emphasis on logo branding and typographic design in campaigns" (p. 4587) impacts participation, starting with the simple question of whether typefaces are perceived to have liberal or conservative leanings and whether subjects' own partisanship impacts how they evaluate them. We find repeated evidence that typefaces have different perceived ideological ratings on a liberal-conservative scale.

It stands to reason that typefaces should have some ideological component, because they are already understood to convey a variety of personality attributes and sentiments (see Brumberger, 2003a, 2003b; Grohmann, 2016; Leonidas, 2012; Shaikh, Chaparro, \& 
Fox, 2006). Political ideology predicts more than candidate choice or issue position: liberal and conservative ideologies are associated with a number of psychological and personality characteristics (Jost, 2006; Jost, Nosek, \& Gosling, 2008). Many of the characteristics used to differentiate liberal and conservative ideologies-i.e. traditional vs. modern, conventional vs. novel-have been used to describe different classifications of typefaces (Osterer \& Stamm, 2013). Moreover, in this era of heightened affective polarization (Iyengar, Lelkes, Levendusky, Malhortra, \& Westwood, 2018; Levendusky, 2009), partisans tend to rate more favorably that which they perceive to share their political views, and vice versa. Possibly, individuals' own partisanship will impact not only how they perceive the ideology of typefaces, but also how favorably they rate them.

This article reports the results of two survey experiments conducted in an American political context demonstrating that typefaces, typeface classifications (serif, sans serif), and typeface styles (bold, italic) are perceived to have ideological qualities. Serifs are rated as more conservative than sans serifs and bold as more conservative than italics. These findings hold regardless of whether a phrase or a name is set in the typeface. Furthermore, an individual's partisanship moderates their perception of typefaces: Republicans rate nearly all typefaces as more conservative, while Democrats perceive them to be more liberal. Finally, there is weak but consistent evidence that affective polarization influences how partisans rate typefaces: significant associations were found between font favorability and ideological rating in the direction of subjects' partisanship.

\section{Typography as a Textual Feature}

There have been several recent calls for a closer inspection of the function of typography in modern communication (see Billard, 2016, 2018; van Leeuwen, 2005, 2006), which necessitate connecting work on type's function to the manner in which designers think about and use it. Although the role type plays in graphic design and communication has long been recognized by practitioners (e.g. Tschichold, 1992; Ward, 1956), the field of political communication has done little in this area aside from studies on ballot design (e.g. Kimball \& Kropf, 2005). Yet while there is little examination of typography in a political context, this is not to say that there has been no empirical study of how it can impact readers. For instance, examinations of typeface legibility have found smaller typeface sizes improve recall of information (Halamish, 2018), script typefaces decrease reading speed and accuracy (Danna, Massendari, Furnari, \& Ducrot, 2018), and larger typefaces can improve how much people think they have learned (Su et al., 2018; Yang, Huang, \& Shanks, 2018).

Although typefaces have therefore been shown to serve functional outcomes, the work cited so far tends to focus on non-aesthetic differences in type usage and tends to be divorced from the aesthetic considerations of graphic designers in their use of typography. Our work aims to put political communication scholarship in further conversation with graphic design practice. As such, we first explore an easily recognizable typographical feature: the use of serifs, or flourishes at the end of strokes (Coles, 2012). In his exegesis The Anatomy of Type, Coles (2012) classifies typefaces in part based on their presence or absence: serif and sans serif. He articulates further differences such as x-height (the difference between the height of capital letterforms relative to lowercase letterforms), stroke contrast (the difference between the thickest and thinnest portions of a letterform), and terminals (the shape used to end strokes). ${ }^{2}$ 
We caution readers, however, in treating this or any classification system as a definitive taxonomy as no such system is universal and "classification is inherently problematic" (Coles, 2012, p. 12). One such problem in the taxonomy we describe is that it does not neatly capture highly stylized display fonts. Technically speaking, display fonts are those that are designed to be used at large point sizes and not in body copy (see Osterer \& Stamm, 2013). Therefore, display fonts as a classification category may include serifs and sans serifs, though many are designed to mimic a particular type of writing such as Stencil, Broadway, and Papyrus typefaces. Furthermore, taxonomies of typography are not structured around functional outcomes of typefaces but rather their anatomy and aesthetics (e. g. McLean, 1980). As such, individual typefaces may not fall cleanly into one category.

Extant work highlights this disconnect between how graphic designers understand typography and empirical work on the topic, much of which also centres on the use of serifs. Hojjati and Muniandy (2014) find sans serif typefaces are more readable on screens; conversely, Lund (1999) concludes after an exhaustive review of extant works that neither classification of typeface is inherently more readable than the other, contradicting what graphic designers believe to be true about typefaces. These contradictions between professional practice and empirical evidence about typeface functionality highlight the need to study the impact of typographic choices in political communication. Because we cannot solely rely on what professionals in the field "know," we must engage in rigorous research to determine if individuals perceive typefaces to have political qualities.

\section{Perceptions of Typefaces and Typeface Classifications}

Research in other fields has already demonstrated the impact of typeface selection on how messages are perceived. Successfully pairing a message with a typographic arrangement is important because a typeface "properly chosen and used, its very personality subtly, often powerfully, reinforces the message" (Gottschall, 1989, p. 124). Empirical work indicates a typeface's "personality" such as whether it is friendly, masculine, or serious is not lost on readers (see Brumberger, 2003b; Shaikh et al., 2006). Such characteristics are important when determining whether a typeface is appropriately used (see also Juni \& Gross, 2008; Kaspar, Wehlitz, von Knobelsdorff, Wulf, \& von Saldern, 2015).

The sentiments and outcomes typefaces elicit are also context-dependent. Huang, $\mathrm{Wu}$, and Shi (2018) found that travelers were more willing to pay for relaxing trips advertised in an "easy-to-read" font rather than a "hard-to-read" font, and vice versa when it came to adventure-oriented trips. Thus, within the context of tourism, congruent fonts impact subjects' willingness to pay. This is also illustrated by Grohmann's (2016) work on gendered branding efforts, which demonstrates that when a feminine script typeface is paired with a brand perceived as similarly feminine, participants were more likely to recommend the product. This research suggests typefaces are not merely receptacles for content and there are "better" typefaces for a particular application. Furthermore, typefaces are capable of eliciting sentiments independently of accompanying content - that is to say the aesthetic or personality of a typeface is not entirely dependent on being placed within a larger context. For instance, individuals perceive Times New Roman and Arial to be more direct and scripts as more elegant (Brumberger, 2003b). In terms of personality traits, Comic Sans is seen as passive and Arial as stable (Shaikh et al., 2006). 
Findings that typefaces have perceived personalities and appropriate uses may indicate certain typefaces are better suited for some electoral candidates over others depending on political contexts. That said, there are some limitations to the expressiveness of typefaces. For instance, when a typeface and message pairing are at odds with one another, typographic choices do not necessarily override explicit message cues see Brumberger, 2003a, 2003b). Though typefaces can express "values such as association, style, identify, differentiation, and beauty" in addition to the encoded textual meaning (Leonidas, 2012, p. 50), what is yet unknown is whether people perceive typefaces through a political lens. Indeed, as Ahmed (2013) argues, graphic designers and general audiences can disagree about the sentiments evoked by a typeface. Certainly, some scholarship assumes that typographic choices are not without influence in a political context as evidenced by Billard's (2016) examination of Gotham in Obama's 2008 campaign and Seidman's (2010) analysis of the same campaign's larger branding efforts. We contribute to this literature on typography, still nascent in political communication, by exploring whether typefaces are perceived to have ideological leanings.

\section{Characteristics of Liberal and Conservative Ideologies}

Political ideology has reemerged as a prominent topic of study due to its increasing correlation with political party identification and its demonstrable relationship to many personality, psychological, and physiological traits (Bafumi \& Shapiro, 2009; Hibbing, Smith, \& Alford, 2014; Jost, 2006). Political ideology is generally understood as a philosophy or belief system that predicts what an individual will think about political issues (Carney, Jost, Gosling, \& Potter, 2008; Jost, 2006). As with ideology writ large, in politics it is a shared, social phenomenon through which adherents interpret reality (Jost, 2006). In the Western world, ideology is conceptualized along a left-right spectrum, with liberal views on the left and conservative on the right (Carney et al., 2008). Ideology has both economic and social dimensions that predict individuals' policy preferences (Feldman \& Johnston, 2014); individuals on the left tend to support equality and promote social change, whereas those on the right are less bothered by inequality and seek to preserve the status quo (Carney et al., 2008, p. 808; Hibbing et al., 2014; Jost, 2006).

Political ideology is also associated with psychological and physiological factors. Ideology predicts levels of certain Big Five traits - consisting of agreeableness, conscientiousness, extraversion, neuroticism and openness to new experiences - that are thought to encompass the essential components of an individual's personality. Liberals are higher in openness to experience than conservatives, whereas conservatives tend to be higher in conscientiousness (Carney et al., 2008; Jost, 2006). Liberals' predisposition to openness has a genetic component, and along with differing brain structures of self-identified liberals and conservatives suggests that ideology may not be merely an acquired preference, but rather something foundationally wired into individuals (Kanai, Feilden, Firth, \& Rees, 2011; Settle, Dawes, Christakis, \& Fowler, 2010).

Ideology pervades thinking and personal expression as well. Conservatives show more "structured and persistent" cognitive styles, whereas liberals are "more responsive to informational complexity, ambiguity, and novelty" (Amodio, Jost, Master, \& Yee, 2007, p. 1). The two groups also differ in their response to negativity, with conservatives exhibiting a greater physiological response and dedicating more psychological resources to negative stimuli 
(Hibbing et al., 2014). Liberals express preferences for "progress, rebelliousness, chaos, flexibility, [and] feminism", whereas conservatives state "explicit preferences for tradition, conformity, order, stability, traditional values, and hierarchy" (Jost et al., 2008, p. 126). The two groups also profess differing attitudes on everything from atheists to Asian food, tattoos to travel, sex to sports (Jost et al., 2008). And while our analysis takes on American perspective, an international meta-analysis found conservativism to be positively correlated with death anxiety, intolerance of ambiguity, and fear of threat and loss, and negatively correlated with uncertainty tolerance, integrative complexity, and self-esteem (Jost, Glaser, Kruglanski, \& Sulloway, 2003).

Given that so many aspects of life appear to fall along ideological lines, and some of the same qualities ascribed to liberals and conservatives can apply to textual design, we want to know if fonts areperceived to have ideological qualities. In addition to testing whether typefaces are seen as ideologically different when comparing one typeface to another, we also wish to examine whether the typeface's style (e.g. bold, italic) can influence perceived ideology.

RQ1: Are a) typeface classifications, b) typeface styles, or c) individual typefaces viewed as more liberal or conservative?

Typefaces do not exist in the abstract; they are used to make visible words and phrases, and thus perceptions of typefaces may be impacted by the messages written in them. Our project is broadly motivated by a desire to understand how the typefaces used in candidate communication might convey ideological meaning, thus the written content may matter as well.

RQ2: Does setting a name or a phrase in a typeface moderate ideological perceptions of the typeface?

\section{Ideological Alignment, Partisan Sorting, and Affective Polarization}

Though political partisanship and ideology refer to different phenomena, they are increasingly associated in contemporary American politics, with liberals identifying as Democrats and conservatives as Republicans (Iyengar \& Westwood, 2015). This phenomenon is known as partisan sorting, or the process by which ideological and party identifications align (Levendusky, 2009). Such sorting is driven by political elites, who signal their party's positions on major issues; voters use these cues to adjust their ideological stances to match their party identification. Issue opinions have become more strongly correlated with party ID and ideology over time (Baldassarri \& Gelman, 2008); self-reported ideology also now accounts for $85 \%$ of variation in candidate choice, and partisans have become more partyloyal over time (Jost, 2006; Levendusky, 2009). Given these relationships, subjects' own partisanship may impact whether they perceive a typeface to have a liberal or conservative quality much in the same way subjects attribute personalities to typefaces (see Brumberger, 2003a).

RQ3: Does subject partisanship moderate ideological perceptions of a typeface? 
As party identification and ideology have become tightly aligned and partisans more loyal, affective polarization has also increased. Affective polarization is defined as "the tendency of people identifying as Republicans or Democrats to view opposing partisans negatively and co-partisans positively" (Iyengar \& Westwood, 2015, p. 691). Increased ideological divergence between the two major American parties, as well as attitudes toward social welfare specifically, appear to drive this phenomenon: as the parties move apart ideologically, affective polarization increases (Rogowski \& Sutherland, 2016). Affective polarization manifests as hostility toward opposing partisans by political elites and results from a lack of social norms shaping behavior toward the other side (Iyengar \& Westwood, 2015). Affective polarization has increased among those who are not ideologically sorted, and across all levels of political knowledge (Lelkes, 2018), and has also been found in partisans' perceptions of a range of nonpolitical objects (see Iyengar et al., 2018). Thus, it is possible that subjects' favorability and ideological ratings of a typeface will be correlated, and show evidence of affective polarization.

RQ4: Is there evidence of affective polarization in subjects' ideological perceptions of a typeface?

\section{Materials and Methods}

To answer these research questions, we conducted two exploratory survey experiments on Amazon's Mechanical Turk (MTurk) platform. ${ }^{3}$ The MTurk platform is particularly wellsuited for survey experiments due to the low cost of recruiting large samples and ease of use (Berinsky, Huber, \& Lenz, 2012). While MTurk samples are not expected to be nationally representative, survey experiments conducted on the platform have repeatedly been shown to produce results highly similar to those conducted with nationally representative probability samples (Berinsky et al., 2012; Coppock, 2018). MTurk samples have also been demonstrated as valid for the study of ideology, though liberals on the platform "hold more characteristically liberal values and attitudes" than those in nationally representative probability samples (Clifford, Jewell, \& Waggoner, 2015, p. 1). Details about each study are reported below.

\section{Study 1}

This first study explores whether typeface classification (serif, sans serif) or typeface style (regular, bold, italic) impacts ideological perceptions of typefaces.

\section{Procedure}

The study was made available to MTurk workers in the United States with an approval rating greater than $85 \%$ who had a minimum of 50 prior HITs approved. After consenting to participate, subjects were shown a short passage ("The quick brown fox jumped over the lazy dog") in Comic Sans, and asked to indicate the degree to which they perceived the typeface as liberal or conservative in order to familiarize themselves with the survey format. Participants were then randomly shown the same "quick brown fox" phrase in one of six typefaces and styles - Times New Roman (TNR) Regular, TNR Bold, TNR Italic, 
Gill Sans Regular, Gill Sans Bold, or Gill Sans Italic - and again asked to rate the typeface, not the phrase itself, as liberal or conservative. At the end of the survey, participants filled out several demographic measures (age, gender, race, party affiliation, and political ideology).

These typefaces were chosen because each represents a different classification - serif and sans serif, respectively - and are among the most well-known and commonly used typefaces. We chose to have participants rate a phrase devoid of political content in order to determine whether the letterforms alone elicited perceptions of ideology, much in the same way that prior work has used essentially meaningless content as a stimulus such as unknown brand names (Grohmann, Giese, \& Parkman, 2013) or the full range of glyphs for a typeface of fonts (Brumberger, 2003b). Using the names of well-known politicians would have made it difficult to separate the effect of prior knowledge of the candidate from that of the typeface.

\section{Measurements}

Subjects' party ID was measured using a categorical variable: respondents chose Democrat (42.15\%), Independent (33.03\%), Republican (22.19\%), and other (2.53\%). Self-reported ideology was measured using a seven-point ordinal variable, choosing between extremely liberal (12.16\%), liberal (24.92\%), slightly liberal (14.08\%), moderate, middle of the road $(21.28 \%)$, slightly conservative $(12.46 \%)$, conservative $(11.25 \%)$, or extremely conservative (3.75\%). Ideology for each stimulus was measured using a feeling thermometer that ranged from -10 (liberal) to 10 (conservative) and was rescaled to range from -1 to 1 .

\section{Participants}

A total of 987 subjects completed the study. The average age of participants was 37.91 $(S D=12.21$, range $19-85) ; 55.62 \%(n=549)$ identified as female, $43.47 \%(\mathrm{n}=429)$ as male, and six subjects identified as trans. Three subjects did not identify their sex. A majority of participants $(73.63 \%)$ identified as White or Caucasian, $7.51 \%$ as Asian American, $7.51 \%$ as African American, $4.46 \%$ as Hispanic or Latino, and $6.90 \%$ as another race or multiple races.

\section{Study 2}

The second study expanded on the first by using a wider range of typefaces, including multiple typefaces within the same family, measuring the impact of setting a phrase or name in the typeface, and including a more granular measure of perceived typeface ideology.

\section{Procedure}

We used MTurk with identical worker qualifications as Study 1 with individuals who completed Study 1 ineligible to participate in Study 2. After consenting, subjects were presented with the phrase "A large fawn jumped quickly" in Comic Sans, which they then rated first in terms of favorability, and then ideology on a subsequent page to familiarize themselves with the survey instruments. Next, participants were assigned to see typefaces displayed in either the "large fawn" phrase or a name (Scott Williams, chosen due to the commonality of both names on the Social Security Administration name list). Each 
participant was randomly assigned to see one serif (Jubilat or TNR), one sans serif (Gill Sans or Century Gothic), and one display (SUNRise, Birds of Paradise or Cloister 预lack Zught). The order in which they saw the typeface swatches was randomly assigned within Qualtrics. Finally, participants answered the same demographic questions from the first study.

Font choices were made deliberately to link the two studies and attempt to determine how much variation exists in perceptions of typefaces. In addition to TNR and Gill Sans, used in both studies, we chose to include Jubilat, a slab serif used in Bernie Sanders' 2016 presidential bid, and Century Gothic, a sans serif and close approximation for Gotham, which Obama used in his 2008 presidential bid. We also included three diverse display typefaces to determine if participants perceived typefaces as different from the serif and sans serif in which most written content is set. The display typefaces consisted of blackletter (Cloister Black Light), script (Birds of Paradise) and a cartoon-esque typeface (Sunrise).

\section{Measurements}

Party ID was measured using a categorical variable with response options Democratic (43.69\%), Independent (33.40\%), Republican (20.77\%), and Other (2.33\%). Self-reported ideology was measured using a seven-point ordinal variable, with subjects responding extremely liberal (12.16\%), liberal (26.01\%), slightly liberal (14.97\%), moderate, middle of the road $(21.42 \%)$, slightly conservative (11.69\%), conservative $(10.76 \%)$, or extremely conservative $(2.90 \%)$. In this study, however, typeface ideology was measured using a feeling thermometer from -100 (liberal) to 100 (conservative) and then rescaled to range from -1 to 1 to mirror the scale used in Study 1. Typeface favorability was measured using a feeling thermometer ranging from -100 (Strongly Dislike) to 100 (Strongly Like).

\section{Participants}

The 1,069 participants reported an average age of $36.75(S D=11.92$, range 18-82); sex was recorded as $52.48 \%(\mathrm{n}=561)$ male and $46.96 \%(\mathrm{n}=502)$ female, along with three transgender subjects, two subjects who selected "other," and one who declined to answer. In terms of race, 70.25\% were White or Caucasian, 9.92\% Asian American, 6.36\% African American, $4.21 \%$ Hispanic or Latino, and $9.26 \%$ other or multiple races.

\section{Results}

Overall, results show that typefaces, typeface classifications, and typeface styles are perceived to have different ideological leanings, and partisanship moderates ideological perceptions of typefaces. We find weak but significant evidence for affective polarization in typeface ratings. Below, we address each research question in order, referencing analysis of both Study 1 and Study 2 where appropriate.

\section{Ideological Leanings of Typeface Families, Styles and Typefaces}

A series of analyses were performed to determine if subjects perceived typeface families, styles, and individual typefaces as more politically liberal or conservative. In Study 1, we consider traditional serif (TNR) against a common sans serif (Gill Sans). A t-test was performed to compare mean ideological ratings since the assumption of homogeneity of 
variance was met. ${ }^{4}$ Subjects rated the serif as more conservative $(M=0.20, S D=0.39)$ than the sans serif $(M=0.07, S D=0.37), t(985)=-5.36, p<.001, d=0.34$. In Study 2 , we expand this analysis to include two serifs (TNR and Jubilat), two sans serifs (Gill Sans and Century Gothic), and a display (Sunrise), script (Birds of Paradise), and a blackletter (Cloister Black Light). Again, the assumption of homogeneity was met, so an ANOVA comparing average ideological scores by typeface classification was performed. Results of the omnibus test were significant, $F(4,3202)=84.36, p<.001, f=0.44, \eta^{2}=.112$. Post-hoc Tukey HSD pairwise comparisons were significant for all typeface classifications except script vs. sans serif; mean ideological scores from left to right were as follows: display $-0.25(S D=0.44)$; sans serif $0.08(S D=0.36)$; script $0.11(S D=0.42)$; serif 0.19 $(S D=0.38)$; blackletter $0.27(S D=0.44)$. Together, results of both studies provide an affirmative answer to RQ1a: serifs are viewed as more conservative than sans serifs, blackletter is the most conservative, scripts are slightly more liberal than serifs, and the cartoonish display typeface is perceived to be the most liberal of all. While the manipulation in Study 1 generated a small-to-medium effect size, in Study 2 we see a much larger effect size likely due to the wider variety of typefaces utilized.

A subsequent analysis of data from Study 1 explored whether typeface styles (bold or italic vs. regular) were perceived to have an ideological lean. An initial ANOVA that pooled results across typeface (TNR and Gill Sans) was performed since data met the assumption of homogeneity of variance; omnibus tests results were significant, $F$ $(2,984)=13.09, p<.001, f=0.16, \eta^{2}=.026$. Post-hoc pairwise comparisons via Tukey HSD test were significant at the $p<.001$ level for italic vs. bold and at the $p<.01$ level for italic vs. regular only; mean ideological ratings from left to right for each style are as follows: Italic $(M=0.05 ; S D=0.37)$, Regular $(M=0.14 ; S D=0.40)$, and Bold $(M=0.20$; $S D=0.37)$. A subsequent analysis was done for each typeface in the study; for TNR an omnibus ANOVA was significant, $F(2,495)=11.63, p<.001, f=0.21, \eta^{2}=.045$. Post-hoc pairwise comparisons were also significant for all styles (Italic, $M=0.09, S D=0.38$; Regular, $M=0.20, S D=0.40$; Bold, $M=0.30, S D=0.36$ ). For Gill Sans, an omnibus ANOVA was also significant, $F(2,496)=3.15, p<.05, f=0.11, \eta^{2}=.013$. However, a posthoc Tukey HSD test found that only Gill Sans Italic $(M=0.01, S D=0.37)$ and Gill Sans Bold $(M=0.11, S D=0.36)$ differed in their ideological rating at the $p<.05$ level. Thus, we can answer RQ1b about typeface style partially in the affirmative: bold style is viewed as more conservative than italic and italic more liberal than regular, though the effects sizes are relatively small, and results vary for individual typefaces.

Finally, the seven typefaces used in Study 2 were examined to determine if individual typefaces differ in their ideological ratings. Because the assumption of homogeneity of variance was not met, a White-adjusted ANOVA was performed. Results of the omnibus test were significant, $F(6,3200)=60.240, p<.001, f=0.33, \eta^{2}=0.118$. A post-hoc Tukey HSD test also found multiple significant pairwise comparisons; Table S1 reporting differences in means is available in the Online Supplement. ${ }^{5}$ Average ideological ratings with standard error bars for each typeface are depicted graphically in Figure 1. Additional t-tests were performed to determine if means differed within typeface families. Within the serif family, TNR $(M=0.21, S D=0.38)$ was viewed as more conservative than Jubilat, though the effect size was negligible $(M=0.17, S D=0.37), t(1067)=-2.03, p<.05, d=0.12$. Within the sans serif family, Century Gothic $(M=0.03, S D=0.36)$ was viewed as more liberal than Gill Sans $(M=0.13, S D=0.37), t(1067)=-4.43, p<.001, d=0.27$. These results provide a partial 


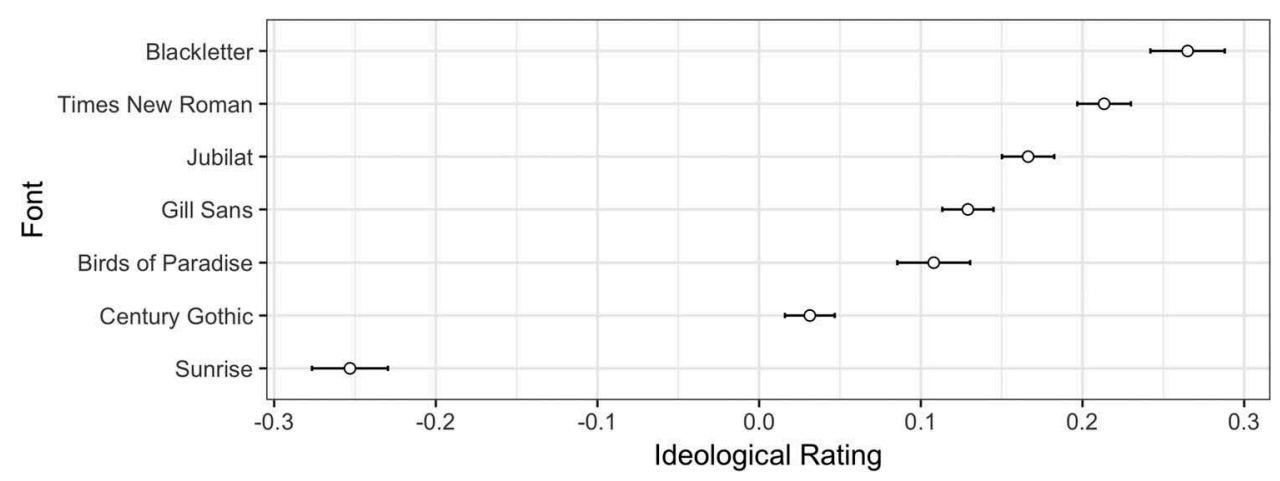

Figure 1. Mean ideology rating of fonts with standard error bars, study 2.

affirmation for RQ1c, in that many of the typefaces tested have different ideological ratings; furthermore, though sans serifs are perceived as more liberal than serifs, within each typeface classification the perception of individual typefaces can vary. Additionally, the overall effect size here is medium-to-large, suggesting that individuals do perceive a wide range of ideological ratings for the typefaces tested, though differences between members of the same classification (serif, sans serif) were relatively small.

\section{Text Content and Ideological Ratings of a Typeface}

A subsequent test explored whether the text set in the typeface moderated ideological ratings. In Study 2, subjects were assigned to see typeface swatches presented either in a phrase ("A large fawn jumped quickly") or a name ("Scott Williams"). First, ideological ratings were pooled across all typefaces; a t-test was performed due to homogeneity of variance. There was no significant difference in ideological rating based on the contents of the text, $t(3205)=1.07, p=.28$. To determine if individual typeface perceptions could be moderated by text content, a linear regression was performed with an interaction term between text content (phrase vs. name) and individual typeface. Again there were no significant results; results are presented in Table S2 in the Online Supplement. The data provide a negative answer to RQ2, since ideological ratings of typefaces are consistent regardless of whether it is used to set a phrase or name.

\section{Partisanship and Ideological Ratings of Typefaces}

Given the partisan nature of the contemporary political environment, it stands to reason that an individual's self-reported party identification might moderate their ideological ratings of typeface classifications, styles, and typefaces. ${ }^{6}$ For these analyses, only selfreported Republicans, Democrats, and Independents are considered. In Study 1, there is a main effect of party: Republicans consistently rate typefaces as more conservative than Independents or Democrats, though there is no main effect for Democrats vs. Independents. Additionally, partisanship moderates perceptions of individual typefaces, providing initial support for RQ3. Republicans and Independents view TNR as significantly more conservative than Gill Sans compared to Democrats; there is no difference 
between Independents and Republicans. Partisanship does not moderate perception of typeface style (bold or italic vs. regular). Results are reported in Table S3 in the Online Supplement.

In Study 2, Republicans and Independents rate all typefaces as more conservative than Democrats, with no difference between Republicans and Independents, providing further partial support for RQ3. When partisanship is interacted with typeface, a number of findings emerge. Controlling for party, Republicans rate Birds of Paradise (the script), Cloister Black Light (the blackletter), and Sunrise (the display typeface) as substantially more liberal than Democrats; the same is true for the latter two typefaces and Republicans vs. Independents. Controlling for party, Independents also rate Birds of Paradise, Cloister Black Light, and Sunrise as more liberal than Democrats. Average ideological ratings for each typeface by subject party are illustrated in Figure 2; regression results are reported in Table S4 in the Online Supplement. ${ }^{7}$

\section{Affective Polarization and Ideological Ratings of Typefaces}

Finally, we consider affective polarization and whether partisans' like or dislike of a typeface is correlated with their ideological rating of it. Affective polarization theorizes that favorability and ideology should be associated in the direction of the partisan's ideological lean, so significant negative correlations for Democrats and positive for Republicans would provide evidence of such a relationship. A series of Spearman-rank correlations were performed due to non-normality in the data; mean favorability of each typeface overall and by partisanship is reported in Table S5 in the Online Supplement.

Overall, there is weak but significant evidence of affective polarization, based on significant correlations between ideological ratings and favorability. The correlation between typeface favorability and ideology is significant for Democrats $(r(465)=-0.06$, $p=.026)$, Republicans $(r(218)=0.48, p<.001)$, and Independents $(r(355)=0.11$, $p<.001$ ). Given that the correlation coefficient is negative (toward the left) for Democrats and positive for Republicans, this provides evidence of affective polarization. A subsequent analysis explored whether this relationship holds for serif and sans serif typefaces. The relationship holds among Democrats for sans serifs $(r(465)=-0.12$, $p=.009)$ and serifs $(r(465)=-0.10, p=.025)$, among Republicans for sans serifs $(r$

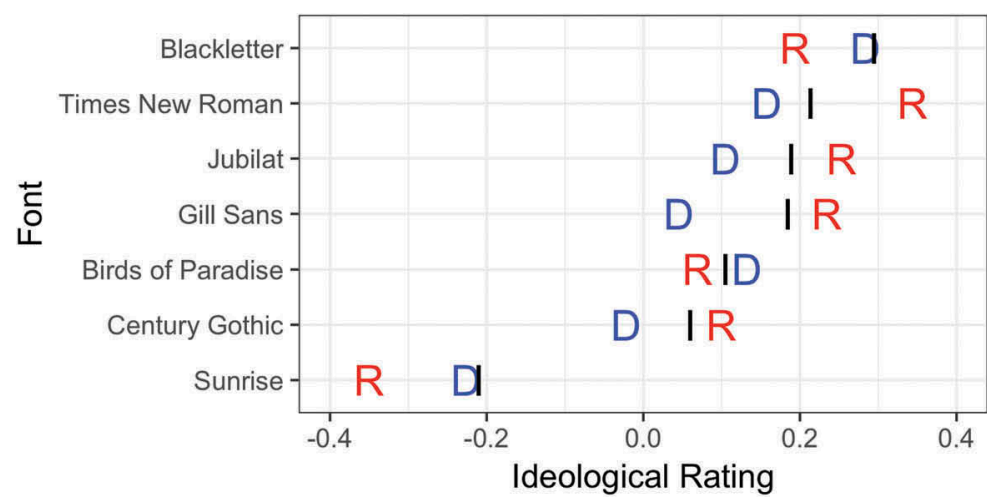

\section{Party Affiliation}

D Democrat

I Independent

R Republican

Figure 2. Mean ideological rating of fonts by party, study 2 . 
$(218)=0.43, p<.001)$ and serifs $(r(218)=0.35, p<.001)$, and among Independents only for serifs $(r(355)=0.12, p=.020)$. However, as correlation coefficients range from -0.21 to 0.43 , results suggests that while a relationship between ideological ratings and typeface favorability exists, it is weak to moderate.

Nevertheless, the data provide an affirmative answer to RQ4: there is evidence of affective polarization in subjects' ratings of typefaces, since ideological and favorability ratings of typefaces by Democrats and Republicans are significantly correlated in the direction of their respective liberal or conservative leanings. The relationship is greatest for Republicans, generating greater correlation coefficients and stronger statistical significance. Among Independents, whose mean self-reported ideology $(3.61, S D=1.31)$ was only marginally right-of-center, favorability of a font is associated with rating it as moreconservative.

\section{Discussion}

Results show that typefaces, typeface classifications, and typeface styles are perceived to have ideological qualities, thus the typographical element of political communication cannot be overlooked as an object of study. Study 2 demonstrates substantial effect sizes in terms of differences in perceived ideology of a wide range of typefaces. Both studies find that sans serifs are viewed as more liberal than serifs, and Study 2 shows even within those classifications significant ideological differences between individual typefaces emerge, though effects are small. There was no significant difference in ideological perceptions of a typeface when it was used to render a name or a phrase, suggesting these effects may be an attribute of the typeface itself. We also find evidence that partisanship moderates ideological perceptions of fonts, with both Republicans and Democrats rating fonts in an ideologically congruent manner. Finally, there is weak but significant evidence of affective polarization, in the form of an association between ideological rating and favorability corresponding to subjects' partisanship.

Thus, the typeface in which a campaign communication is rendered may have an impact on how voters perceive it, suggesting that typeface and graphic design are worthy areas for future research. This work builds on prior work demonstrating that typefaces are seen as possessing differing personality attributes (see Brumberger, 2003a, 2003b; Grohmann, 2016; Leonidas, 2012; Shaikh et al., 2006), and contributes to our understanding of the overwhelming power of partisanship and ideology in contemporary American politics. While it is perhaps not a surprise that typefaces are viewed as liberal or conservative given the other qualities that have been ascribed to them, the degree to which subjects' own partisanship influences their perception of typefaces and whether or not they like them suggests that typographical design choices may have consequences for how political messages are received.

\section{Practical Implications}

Our results have clear implications for political campaign professionals: typeface conveys ideology, so choose a candidate's typographical identity carefully. Practitioners can use these results to choose a typeface classification that harmonizes with a candidate's ideology or to moderate that ideology to appeal to specific groups of voters. Graphic designers 
looking to create a more conservative or liberal look for their candidates can also draw on our findings showing that the particular style applied to a typeface matters: bolder, thicker letterforms were seen as more conservative and italicized letterforms as more liberal. Therefore, graphic designers who wish to use a particular typeface for aesthetic purposes or because it elicits other personality attributes for a candidate may be able to utilize the style applied to the letterforms to influence perceptions of political ideology.

Additionally, we found that participants rated typefaces they liked as more aligned with their own ideology. This highlights the importance of professional graphic designers in the creation of campaign materials. Until the causal directionality of this relationship is established, we recommend practitioners should spend time and energy selecting likable typefaces that are also ideologically congruent with their candidates. Based on our own findings and those by past researchers such as Ahmed (2013), graphic designers should take care to avoid more disliked typefaces, since they may have the unintended consequence of generating backlash.

\section{Limitations}

The primary limitation in these findings comes from the choice to test a small, specific set of typefaces. In order to assess whether key typeface attributes (e.g. the presence of serifs) influenced perceptions of political ideology, we collapsed typefaces into broad typeface classifications (serif, sans serif) based on how graphic designers understand letterforms (see McLean, 1980). We also limited the number of typefaces tested due to concerns about statistical power. In particular, the display fonts used here do not exhaust the diversity of such typefaces. Future work that explores the ideological nature of such typefaces may find display typefaces that mimic other forms of writing will always be seen as liberal because they are relatively new developments in the long history of typography (see McLean, 1980). Conversely, display typefaces may be seen as liberal or conservative depending on the context or history they evoke (e.g. Stencil, Broadway, Papyrus). And while we find an association between font favorability and ideological rating affirming affective polarization, we cannot establish a causal direction of this relationship as we did not manipulate typeface favorability. It is possible that ideology drives font favorability or vice versa.

\section{Toward a Future Research Agenda}

This was an exploratory study that suggests many avenues for future research to build on the results herein. Our findings illuminate the need for additional studies to determine exactly why individuals perceive typefaces as liberal or conservative, and what drives affective polarization of typefaces. Serif typefaces were among the first developed for professional printing and thus may be recognized as conservative because they represent an established status quo (Brennan \& Hamlin, 2016). Future work should determine which elements of typography elicit liberal or conservative ratings, such as $\mathrm{x}$-height and stroke variation. Additional research should also examine the effect of typographic choices when participants are rating names of known political figures rather than apolitical phrases. Research building on our findings could examine the effect of typeface on real politicians' names (e.g. are typeface ratings different when they say "Hillary Clinton" or "Donald Trump"?). Additional work is also needed to determine if typography can 
counteract or harmonize with what is already known about a political candidate. As in past work (Brumberger, 2003a, 2003b) typographic choices may not overcome prior knowledge or beliefs about people, policies, or parties.

Possibly the typefaces selected caused conscious or subconscious associations with their use elsewhere: for instance, Republicans tended to view the blackletter typeface - long a mainstay of newspaper mastheads - as more liberal than Democrats or Independents. This may be related to Republican attitudes toward media such as the New York Times or Washington Post, especially in light of recent attacks on mainstream news organizations as "fake news" by political figures. Participants who are regular newspaper consumers may have the inverse reaction, trusting content or people associated with blackletter typefaces. Subsequent studies should ask participants about their familiarity and preexisting associations with each typeface.

Finally, the findings presented here cannot yet be taken to mean that typeface choice can influence perceptions of a candidate. Additional work is needed to determine whether perceptions of the typeface spill over into perceptions of the person whose name is written in it, or if perceived race or gender of a candidate moderates perceptions of the typeface itself (see Brumberger, 2003a). Also, it remains to be seen if typefaces only become ideological when placed within a political context. For instance, a typeface may be perceived to have a stronger ideological tilt when used to set a candidate's name, as opposed to that of a consumer product. And while our study was conducted within a U.S. context, it is possible that perceptions of typography vary across cultures. Indeed, it would be surprising if our findings were shown to be stable globally given the degree to which the two spheres of interest in this study - politics and art - can vary between cultures.

\section{Conclusion}

This study demonstrates empirically that typeface plays a role in American political communication, conveying ideology through the anatomy of its letterforms. Ergo, candidates' choice of typeface may produce unexpected or unintended consequences in terms of how they are perceived. As such, typefaces should be further explored as a component of how candidates communicate to voters, whether explicitly or implicitly. Through the two survey experiments presented here, we lay the groundwork for future work that identifies relationships between typefaces and persuasive outcomes in political communication. We also demonstrate the degree to which individuals' own partisanship impacts how they rate typefaces: people tend to see typefaces as ideologically congruent, and when they do so their favorability of the typeface increases. Thus affective polarization is present in partisans' perceptions of typefaces, which may well spill over into their attitudes about whatever text is written in the typeface. Further research is needed to understand the role that typography plays in shaping attitudes toward political communications and their sources.

\section{Notes}

1. While the term "font" may be more familiar to readers, we use the phrase "typeface" throughout this paper, as fonts are digital files containing the collection of glyphs used in design programs, whereas typefaces are the set of displayed characters. 
2. Coles (2012) also distinguishes between serifs and slab serifs based on the shape of the flourish or foot of the letterform. Whereas the flourishes on traditional serifs are to some degree curved, on slab serifs the feet are angular and geometric.

3. Materials for the experiments including survey text and font swatches are available on the Open Science Framework (Haenschen \& Tamul, 2019).

4. A separate analysis was conducted using linear regression to control for the effects of participant age, sex, and race on ideological ratings. Demographic covariates never approached anything more than marginal significance, and never impacted the main effects of typeface, typeface family, or typeface style on ideological rating.

5. The online supplement is available at https://osf.io/f65wb/.

6. Partisanship and ideology are not the same thing, even in this era of highly sorted partisans (Levendusky, 2009), thus before utilizing subject partisanship as a variable we affirmed that it met our expectations regarding ideological self-placement. In Study 2, subjects' self-reported partisanship and ideology were both measured and compared; as expected, Democrats $(M=$ $2.33, S D=1.12)$, Independents $(M=3.51, S D=1.30)$, and Republicans $(M=5.45, S D=1.14)$, and had significantly different average ideological scores, $F(2,546.86)=543.47, p<.001$; posthoc tests were all $p<.001$. The same was true for Study 2, in which Democrats $(M=2.31, S D$ $=1.09)$, Independents $(M=3.61, S D=1.31)$, and Republicans $(M=5.33, S D=1.16)$ had significantly different mean ideological self-reports, $F(2,554.4)=536.87, p<.001$. Mean ideology scores by party identification fall along the expected left-right spectrum, with Independents in the middle.

7. We conducted a similar analysis with the Comic Sans data generated by subjects, but found only partially consistent results. In Study 1, Republicans rated Comic Sans as more conservative than Democrats or Independents; in Study 2 there were no significant differences in ideological ratings of the font by party.

\section{Disclosure statement}

No potential conflict of interest was reported by the authors.

\section{Data availability statement}

The data described in this article are openly available in the Open Science Framework at https://doi. org/10.17605/OSF.IO/F65WB.

\section{Open Scholarship}

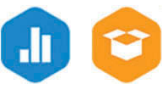

This article has earned the Center for Open science badges for Open Data and Open Materials through Open Practices Disclosure. The materials are openly accessible at https://doi.org/10.17605/ OSF.IO/F65WB.

\section{Notes on contributors}

Dr. Katherine Haenschen is an Assistant Professor in the Department of Communication at Virginia Tech. Her research focuses on the intersection of digital media and political participation, and digital analytics. She has previously published in the Journal of Communication, Political Communication, and Social Science Computer Review. 
Dr. Daniel J. Tamul is an Assistant Professor in the Department of Communication at Virginia Tech. His research examines how news narratives and their formal features impact persuasive outcomes such as perceptions of stigmatized social groups and attitudes. His work has appeared in Journalism \& Mass Communication Quarterly, Computers in Human Behavior, and International Journal of Communication.

\section{ORCID}

Katherine Haenschen (1) http://orcid.org/0000-0003-0191-2880

Daniel J. Tamul (10) http://orcid.org/0000-0002-0421-380X

\section{References}

Ahmed, M. (2013). Typeface persona: Investigating Gotham's suitability for Obama's 2008 presidential campaign (Doctoral Dissertation), Howard University, Washington, DC.

Amodio, D. M., Jost, J. T., Master, S. L., \& Yee, C. M. (2007). Neurocognitive correlates of liberalism and conservatism. Nature Neuroscience, 10(10), 1246-1247. doi:10.1038/nn1979

Bafumi, J., \& Shapiro, R. Y. (2009). A new partisan voter. The Journal of Politics, 71(1), 1-24. doi:10.1017/S0022381608090014

Baldassarri, D., \& Gelman, A. (2008). Partisans without constraint: Political polarization and trends in American public opinion. American Journal of Sociology, 114(2), 408-446. doi:10.1086/590649

Benoit, P. J., \& Benoit, W. L. (2009). Criteria for evaluating political campaign webpages. Southern Communicatinon Journal, 70(3), 230-247. doi:10.1080/10417940509373329

Berinsky, A. J., Huber, G. A., \& Lenz, G. S. (2012). Evaluating online labor markets for experimental research: Amazon.com's Mechanical Turk. Political Analysis, 20(3), 351-368. doi:10.1093/pan/ mpr057

Billard, T. J. (2016). Fonts of potential: Areas for typographic research in political communication. International Journal of Communication, 10, 4570-4592.

Billard, T. J. (2018). Citizen typography and political brands in the 2016 US presidential election. Marketing Theory, 18(3), 421-431. doi:10.1177/1470593118763982

Brennan, G., \& Hamlin, A. (2016). Conservative value. The Monist, 99, 352-371. doi:10.1093/ monist/onw010

Brumberger, E. R. (2003a). The rhetoric of typography: The awareness and impact of typeface appropriateness. Technical Communication, 50(2), 224-231.

Brumberger, E. R. (2003b). The rhetoric of typography: The persona of typeface and text. Technical Communication, 50(2), 206-223.

Carney, D. R., Jost, J. T., Gosling, S. D., \& Potter, J. (2008). The secret lives of liberals and conservatives: Personality profiles, interaction styles, and the things they leave behind. Political Psychology, 29(6), 807-840. doi:10.1111/j.1467-9221.2008.00668.x

Clifford, S., Jewell, R. M., \& Waggoner, P. D. (2015). Are samples drawn from Mechanical Turk valid for research on political ideology? Research \& Politics, 1-9. doi:10.1177/2053168015622072

Coles, S. (2012). The anatomy of type: A graphic guide to 100 typefaces. New York, NY: Quid Publishing.

Coppock, A. (2018). Generalizing from survey experiments conducted on Mechanical Turk: A replication approach. Political Science Research and Methods, 1-16. doi:10.1017/psrm.2018.10

Cosgrove, K. M. (2012). Political branding in the modern age: Effective strategies, tools and techniques. In J. Lees-Marshment (Ed.), Routledge handbook of political marketing(pp. 122138). New York, NY: Routledge.

Danna, J., Massendari, D., Furnari, B., \& Ducrot, S. (2018). The optimal viewing position effect in printed versus cursive words: Evidence of a reading cost for the cursive font. Acta Psychologica, 188, 110-121. doi:10.1016/j.actpsy.2018.06.003 
Feldman, S., \& Johnston, C. (2014). Understanding the determinants of political ideology: Implications of structural complexity. Political Psychology, 35(3), 337-358. doi:10.1111/ pops. 12055

Gottschall, E. M. (1989). Typographic communications today. Cambridge, MA: The MIT Press.

Grohmann, B. (2016). Communicating brand gender through type fonts. Journal of Marketing Communications, 22(4), 403-418. doi:10.1080/13527266.2014.918050

Grohmann, B., Giese, J. L., \& Parkman, I. D. (2013). Using type font characteristics to communicate brand personality of new brands. Journal of Brand Management, 20(5), 389-403. doi:10.1057/ bm. 2012.23

Haenschen, K., \& Tamul, D. (2019, September 20). Typography and ideology (Fonts 1.0). doi:10.17605/OSF.IO/F65WB

Halamish, V. (2018). Can very small font size enhance memory? Memory \& Cognition, 46, 979-993. doi:10.3758/s13421-018-0816-6

Heller, S. (2008, April 21). McCain's optimum look. The New York Times. Retrieved from https:// campaignstops.blogs.nytimes.com/2008/04/21/mccains-optimum-look/

Hibbing, J. R., Smith, K. B., \& Alford, J. R. (2014). Differences in negativity bias underlie variations in political ideology. Behavioral and Brain Sciences, 37(3), 297-307. doi:10.1017/ S0140525X13001192

Hojjati, N., \& Muniandy, B. (2014). The effects of font type and spacing of text for online readability and performance. Contemporary Educational Technology, 5(2), 161-174.

Huang, Y., Wu, J., \& Shi, W. (2018). The impact of font choice on web pages: Relationship with willingness to pay and tourism motivation. Tourism Management, 66, 191-199. doi:10.1016/j. tourman.2017.12.010

Iyengar, S., Lelkes, Y., Levendusky, M., Malhortra, N., \& Westwood, S. J. (2018). The origins and consequences of affective polarization in the United States. Annual Review of Political Science. doi:10.1146/annurev-polisci-051117-073034

Iyengar, S., \& Westwood, S. J. (2015). Fear and loathing across party lines: New evidence on group polarization. American Journal of Political Science, 59(3), 690-707. doi:10.1111/ajps.12152

Jackson, B. (2012, September 22). Romney campaign looking into copyright claim. Buzzfeed News. Retrieved from https://www.buzzfeednews.com/article/buzzfeednews/about-buzzfeed-news

Jost, J. T. (2006). The end of the end of ideology. American Psychologist, 61(7), 651-670. doi:10.1037/0003-066X.61.7.651

Jost, J. T., Glaser, J., Kruglanski, A. W., \& Sulloway, F. J. (2003). Political conservatism as motivated social cognition. Psychological Bulletin, 129, 339-375. doi:10.1037/0033-2909.129.3.339

Jost, J. T., Nosek, B. A., \& Gosling, S. D. (2008). Ideology: Its resurgence in social, personality, and political psychology. Perspectives on Psychological Science, 3(2), 126-136. doi:10.1111/j.17456916.2008.00070.x

Juni, S., \& Gross, J. S. (2008). Emotional and persuasive perception of fonts. Perceptual and Motor Skills, 106(1), 35-42. doi:10.2466/pms.106.1.35-42

Kanai, R., Feilden, T., Firth, C., \& Rees, G. (2011). Political orientations are correlated with brain structure in young adults. Current Biology, 21(8), 677-680.

Kaspar, K., Wehlitz, T., von Knobelsdorff, S., Wulf, T., \& von Saldern, M. A. O. (2015). A matter of font type: The effect of serifs on the evaluation of scientific abstracts. International Journal of Psychology, 50(5), 372-378. doi:10.1002/ijop.12160

Kimball, D. C., \& Kropf, M. (2005). Ballot design and unrecorded votes on paper-based ballots. Public Opinion Quarterly, 69(4), 508-529. doi:10.1093/poq/nfi054

Lelkes, Y. (2018). Affective polarization and ideological sorting: A reciprocal, albeit weak relationship. The Forum, 16(1), 67-79. doi:10.1515/for-2018-0005

Leonidas, G. (2012). Type design and development. In J. Tselentis, A. Haley, R. Poulin, T. Seddon, G. Leonidas, I. Saltz, ... T. Alterman (Eds.), Typography referenced: A comprehensive visual guide to the language, history, and practice of typography(pp. 30-51). Deverly, MA: Rockport Publishing.

Levendusky, M. (2009). The partisan sort: How liberals became Democrats and conservatives became Republicans. Chicago, IL: University of Chicago Press. 
Lund, O. (1999). Knowledge construction in typography: The case of legibility research and the legibility of sans serif typefaces (Doctoral Dissertation), The University of Reading, Reading, UK.

McLean, R. (1980). The Thames and Hudson manual of typography. London, UK: Thames and Hudson.

O'Kane, C. (2019, January 21). Kamala Harris' campaign launch pays tribute to Shirley Chisholm's 1972 run. CBS News. Retrieved from https://www.cbsnews.com/news/kamala-harris-2020-presi dential-campaign-logo-pays-tribute-to-shirley-chisholm/

Osterer, H., \& Stamm, P. (2013). Adrian Frutiger typefaces: The complete works (2nd ed.). Basel, Switzerland: Birkhäuser Verlag.

Rainbird, D. (2012, July 23). Campaign font war: Gotham vs. Mercury. Salon. Retrieved from https://web.archive.org/web/20191130200847/https://www.salon.com/2012/07/23/gotham_vs_ mercury_the_presidential_campaign's_real_issues_salpart/

Rogowski, J. C., \& Sutherland, J. L. (2016). How ideology fuels affective polarization. Political Behavior, 38(2), 485-508. doi:10.1007/s11109-015-9323-7

Seidman, S. A. (2010). Barack Obama's 2008 campaign for U.S. presidency and visual design. Journal of Visual Literacy, 29, 1-27. doi:10.1080/23796529.2010.11674671

Settle, J. E., Dawes, C. T., Christakis, N. A., \& Fowler, J. H. (2010). Friendships moderate an association between dopamine gene variant and political ideology. The Journal of Politics, 72(4), 1189-1198. doi:10.1017/S0022381610000617

Shaikh, A. D., Chaparro, B. S., \& Fox, D. (2006). Perception of fonts: Perceived personality traits and uses. Usability News, 8(1), 1-6.

Su, N., Li, T., Zheng, J., Hu, X., Fan, T., \& Luo, L. (2018). How font size affects judgements of learning: Simultaneous mediating effect of item-specific beliefs about fluency and moderating effect of beliefs about font size and memory. PLOS ONE, 13(7), 1-14. doi:10.1371/journal.pone/ 0200888

Tschichold, J. (1992). Treasury of alphabets and lettering: A source book of the best letter forms of past and present for sign painters, graphic artists, commercial artists, typographers, printers, sculptors, architects, and schools of art and design. New York, NY: Norton \& Company.

van Leeuwen, T. (2005). Typographic meaning. Visual Communication, 4(2), 139-143. doi:10.1177/ 1470357205053749

van Leeuwen, T. (2006). Towards a semiotics of typography. Information Design Journal, 14(2), 139-155. doi:10.1075/idj.14.2.06lee

Ward, B. (1956). The crystal goblet: Sixteen essays on typography. (H. Jacob ed.). Cleveland, OH: World Publishing Company.

Yang, C., Huang, T. S. T., \& Shanks, D. R. (2018). Perceptual fluency affects judgements of learning: The font size effect. Journal of Memory and Language, 99, 99-110. doi: 10.1016/j.jml.2017.11.005 